\title{
North is up(hill): Route planning heuristics in real-world environments
}

\author{
Tad T. Brunyé, Caroline R. Mahoney, and Aaron L. Gardony \\ U.S. Army Natick Soldier Research, Development and Engineering Center, Natick, Massachusetts \\ and Tufts University, Medford, Massachusetts
}

AND

\author{
Holly A. TAYlor \\ Tufts University, Medford, Massachusetts
}

\begin{abstract}
Navigators use both external cues and internal heuristics to help them plan efficient routes through environments. In six experiments, we discover and seek the origin of a novel heuristic that causes participants to preferentially choose southern rather than northern routes during map-based route planning. Experiment 1 demonstrates that participants who are tasked to choose between two equal-length routes, one going generally north and one south, show reliable decision preferences toward the southern option. Experiment 2 demonstrates that participants produce a southern preference only when instructed to adopt egocentric rather than allocentric perspectives during route planning. In Experiments 3-5, we examined participants' judgments of route characteristics and found that judgments of route length and preferences for upper relative to lower path options do not contribute to the southern route preference. Rather, the southern route preference appears to be a result of misperceptions of increased elevation to the north (i.e., north is up). Experiment 6 further supports this finding by demonstrating that participants provide greater time estimates for north- than for equivalent south-going routes when planning travel between U.S. cities. Results are discussed with regard to predicting wayfinding behavior, the mental simulation of action, and theories of spatial cognition and navigation.
\end{abstract}

"I always like going south. Somehow it feels like going downhill."

Treebeard, The Lord of the Rings

Wayfinding, or moving purposefully from origin to destination, is a highly complex yet exceedingly common human task. Sometimes we move unaided, retrieving and applying mental representations of environments to guide us from place to place; other times, we move aided by external representations of environments, such as road maps and global positioning systems (GPS). In the absence of digital support, travelers must develop a route plan that details the path segments and turn angles that guide effective movement through an environment (Golledge, 1999; Montello, 2005). Six experiments provide the first evidence of a heuristic that biases the route-planning process and produces a southern route preference, wherein travelers disproportionately select southern rather than equivalent-distance northern routes during planning.

\section{Route-Planning Asymmetries}

In most cases, the ostensible goal of wayfinding is to move from one place to another as quickly and effortlessly as possible. This process is accomplished by reviewing the spatial relationship between an origin and a destination, identifying and comparing route options, and selecting the most viable path (Benshoof, 1970; Bovy \& Stern, 1990; Gärling, Lindberg, \& Mäntylä, 1983; Golledge, 1995; Jacoby, 1917; Seneviratne \& Morrall, 1986). When interviewed, most people agree that they can identify the shortest and most efficient route quickly and without much effort, particularly when using a road map (Gärling \& Gärling, 1988; Ueberschaer, 1971). People are not generally aware, however, that their route selections are affected by several implicit strategies for deciding which route to choose when there is no objectively correct decision (Bailenson, Shum, \& Uttal, 1998; Christenfeld, 1995; Conroy Dalton, 2003; Gärling \& Gärling, 1988; Golledge, 1995; Hochmair \& Karlsson, 2005; Hölscher, Meilinger, Vrachliotis, Brösamle, \& Knauff, 2006; Janzen, Herrmann, Katz, \& Schweizer, 2000; Seneviratne \& Morrall, 1986; Wiener, Lafon, \& Berthoz, 2008; Wiener \& Mallot, 2003; Wiener, Schnee, \& Mallot, 2004).

Christenfeld (1995) found that when no objectively correct decision exists during wayfinding, people use implicit strategies to minimize the mental and physical effort involved in moving through the environment. Indeed, some work suggests that people will simplify route plans 
in an attempt to reduce the costs associated with planning and executing wayfinding sequences (i.e., Freksa, 1999; Levine, 1982). Further work demonstrates that travelers use least-angle strategies, choosing routes that deviate minimally from the global direction of a designated goal destination (Conroy Dalton, 2003; Hochmair \& Frank, 2002; Hochmair \& Karlsson, 2005); initial segment strategies, choosing routes on the basis of their initial straightness as they depart from an origin (Bailenson et al., 1998; Bailenson, Shum, \& Uttal, 2000); and also choose routes containing the fewest number of landmarks and turns (Sadalla \& Staplin, 1980; Seneviratne \& Morrall, 1986). Interestingly, these strategies are sometimes relied on even when they result in selecting a relatively inefficient route. As such, predicting wayfinding behavior is best accomplished not only by the participants' knowing which route is shortest or most efficient, but also by their considering several heuristics or implicit strategies that guide decision making but seem to be outside of participants' awareness (Bailenson et al., 1998, 2000; Christenfeld, 1995). Identifying the full range of wayfinding heuristics is critical for the prediction of wayfinding behavior in applied contexts (i.e., in lost individuals, Heth \& Cornell, 1998; or for environmental engineering, Gärling \& Gärling, 1988; Raubal, 2002; Weisman, 1981), and the theoretical and computational modeling of human spatial behavior (Golledge, 1999; Kuipers, 2000; Montello, 1998; Yoshino, 1991).

\section{EXPERIMENT 1 Southern Route Preference}

In a recent study in which the influence of nonspatial variables on wayfinding performance (e.g., time, mode of locomotion, load carriage) was examined, we found evidence that participants selected southern rather than northern routes at a rate exceeding that predicted by chance. Given that this earlier research was not specifically designed to test wayfinding preferences, we conducted a series of experiments to directly examine this apparent southern route selection bias. In our first two experiments, we had participants plan routes between origin-destination pairs using modified maps of Pittsburgh and Chicago. The design of the maps and wayfinding pairs created a northsouth dilemma, an east-west dilemma, or no dilemma. In the dilemma trials, we presented equal-length alternative routes between wayfinding pairs that went either to the south or north or to the east or west. The filler (nodilemma) trials did not have competing route possibilities (i.e., one of the possible routes was perceptibly shorter). On the dilemma trials, we measured the extent to which participants chose north versus south and east versus west route options, to examine whether route planning deviates from chance behavior (50/50). We expected that if participants show a southern route preference, their selection of southern versus northern routes would depart from chance.

Given work demonstrating that the application of wayfinding heuristics might vary as a function of the perspectives adopted by participants (Janzen et al., 2000), we also examined the perspectives spontaneously adopted by participants during route planning and how they might modulate any southern preference. In general, when describing a route, one can adopt an egocentric, allocentric, or mixed perspective on an environment (Levelt, 1982; Taylor \& Tversky, 1992a, 1992b). An egocentric (firstperson) perspective describes an environment from the ground level, referencing movements and turns to the dynamic position of an entity within the environment (e.g., go forward, turn left, turn right, go back). An allocentric perspective, in contrast, describes an environment from a bird's-eye view, referencing movement and turns to a fixed position outside of the environment, typically using cardinal terms (e.g., north, south, east, west). Maps typically depict the world in an allocentric perspective, maintaining a bird's-eye view of an environment. As such, adopting an egocentric perspective to describe movement through a map-based environment involves complex mental imagery and rotation in order to actively imagine oneself moving through the environment (i.e., Brunyé, Rapp, \& Taylor, 2008; Brunyé \& Taylor, 2008a, 2008b; FincherKiefer, 2001; B. Tversky, 2009). Both perspectives are commonly used, and often mixed, when describing movement through an environment (Taylor \& Tversky, 1992a).

Adopting different perspectives on an environment can affect the information that people seek, gather, memorize, and can subsequently apply (Brunyé \& Taylor, 2009; Magliano, Cohen, Allen, \& Rodrigue, 1995; Taylor, Naylor, \& Chechile, 1999; B. Tversky, 2009; van Asselen, Fritschy, \& Postma, 2006). It might be the case that increased first-person immersion during route planning may exacerbate route-planning preferences by activating the same heuristics that are used during actual, real-world wayfinding. This hypothesis is based on work demonstrating that taking alternate perspectives can differentially guide the mental simulation of actions, promote immersed (or grounded) understanding, and activate mental representations that are common to those activated during action execution (Barsalou, 2008; Brunyé, Ditman, Mahoney, Augustyn, \& Taylor, 2009; Ditman, Brunyé, Mahoney, \& Taylor, 2010; Fischer \& Zwaan, 2008; Glenberg, 2007; Glenberg \& Kaschak, 2002; Richardson, Spivey, Barsalou, \& McRae, 2003; Ruby \& Decety, 2001).

\section{Method}

\section{Participants and Design}

Sixty-four Tufts University undergraduate students (45 female; mean age $=19.9$ years) participated for monetary compensation. We used a repeated measures design with three trial types: northsouth dilemma, east-west dilemma, and no dilemma. We measured which route option the participants chose in the two dilemma conditions (north-south and east-west). We also recorded whether the participants used egocentric, allocentric, or mixed terms to describe their chosen routes.

\section{Materials}

Maps. Two real-world environments were chosen from suburban Pittsburgh and Chicago, using the Google Maps utility at a zoom level of 1 in. $=290$ linear ft. Each map measured 1,200 $\times 793$ pixels and contained a compass rose and 13 landmarks: a park, a chapel, a dance club, a bike shop, a hotel, a café, an information booth, a theater, a grocery store, a restaurant, and three metro stations. Each 


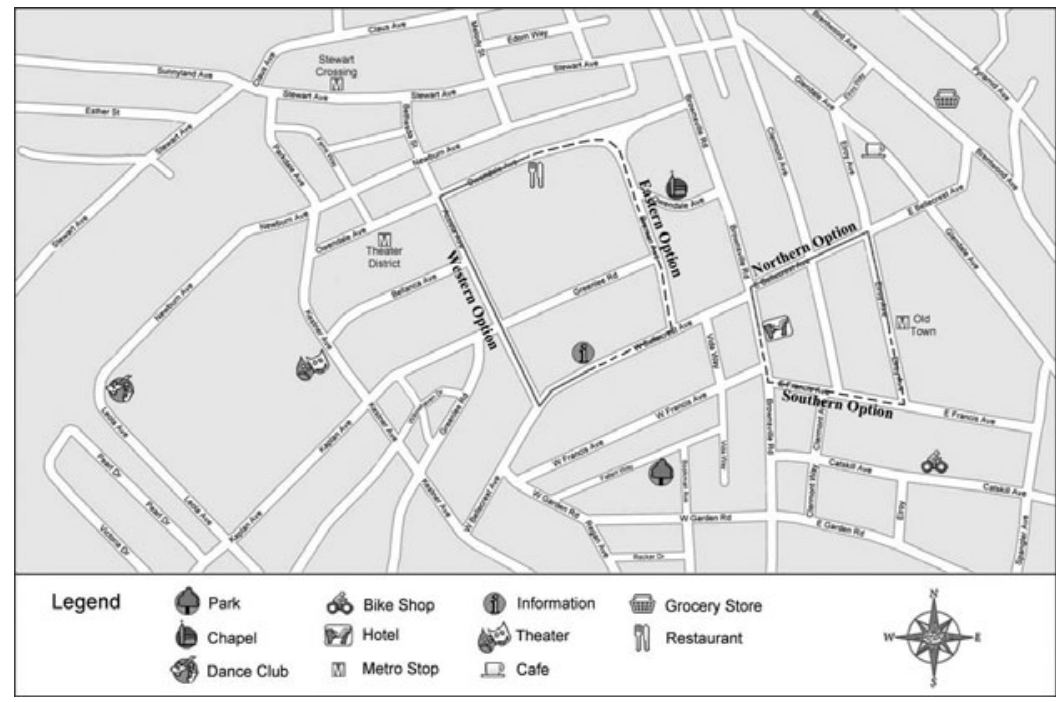

Figure 1. A sample map of the Pittsburgh neighborhood (in original orientation) with two example dilemma trials: north-south (hotel to Old Town Metro stop) and east-west (restaurant to information booth).

landmark was depicted with a representative icon and was defined in a legend (see Figure 1). Two versions of the maps were created, one in the original orientation and one rotated $180^{\circ}$ (maintaining a northup compass rose orientation and properly oriented street-name text); these two versions were used across participants to control for effects of differential route complexity (e.g., number of turns; Seneviratne \& Morrall, 1986) in dilemma pair options (i.e., northern routes became southern routes in the second map version and vice versa; the same applied to the east-west dilemma pairs).

Routes. A total of 20 routes were developed for each of the two maps. The routes and landmark locations were modified such that each map contained 10 dilemma and 10 nondilemma (filler) origindestination pairs. Of the 10 dilemma pairs, 5 had origin-destination pairs positioned on a north-south axis with respect to one another with routes running to the east or to the west between them (eastwest dilemma) and 5 had origin-destination pairs positioned on an east-west axis with respect to one another with routes running to the north or to the south between them (north-south dilemma). The dilemma trials contained two equal-length route options between two landmarks; in an east-west dilemma, the two route options went east and west, and in a north-south dilemma, the two route options went north and south. Across all 20 routes within a map, each landmark was referenced at least once (and no more than three times) as an origin or destination, and the distances between the origin and the destination in a pair varied widely within a single map (Pittsburgh, $M=6.13, S D=2.33$; Chicago, $M=7.0, S D=1.63$ ). Two versions of the routes were created by swapping origins and destinations (i.e., park to information booth became information booth to park); these two versions were used across participants to control for effects of route complexity immediately surrounding an origin (i.e., Bailenson et al., 1998, 2000) and also to control for the possibility that the participants would prefer routes that allowed right turns (i.e., righton-red affordances; Scharine \& McBeath, 2002).

\section{Procedure}

The participants sat at a 19-in. monitor connected to a Macintosh computer running SuperLab 4.0. The participants completed two study-test blocks, one for each of the two maps (Pittsburgh, Chicago), in counterbalanced order across participants. During the study phase, the participants familiarized themselves with the map, presented on the computer monitor for $2 \mathrm{~min}$. The experimenter then probed for landmark knowledge by asking the participants to verbally confirm whether they knew each landmark location as it was read aloud. Once the participants affirmed their landmark location knowledge, they received 20 route-planning trials, one at a time in random order. Each trial was read aloud by the experimenter and included an origin, a destination, and the question, What is the best route from the [origin] to the [destination]? The participants were told that the best route was the one that was shorter and/or faster. The participants verbally reported a route, and the experimenter digitally recorded their response; no formal response time limit was established, and most participants began reporting a route within 5-10 sec of being probed. This procedure was then repeated for the second map and its corresponding trials, for a total of 10 north-south and 10 east-west dilemma trials.

\section{Results}

\section{Scoring and Analysis}

For each trial, we recorded the chosen route and the perspective used to describe the route. On the dilemma trials, the chosen route was either north or south, or east or west. On the nondilemma filler trials, the route was not associated with directional conflict and was therefore not further analyzed. Perspectives were recorded as either egocentric (the participant used the terms forward, left, right), allocentric (the participant used the terms north, south, east, west), or mixed (any combination of egocentric and allocentric). We performed our analyses separately for the two dilemma types and based them on the adopted perspective (egocentric, allocentric, mixed) and the proportion of chosen routes in a dilemma trial (north or south, east or west). The results did not differ as a function of map (Pittsburgh, Chicago) or map version (original, rotated $180^{\circ}$ ), and all analyses were therefore collapsed across these two factors. Effect size is reported using Cohen's $d$.

\section{Route Choice}

Our first set of analyses was focused on the extent to which north-south or east-west dilemma trials were as- 
sociated with decisions that departed from chance $(50 \%)$. Overall, on the north-south dilemma trials, the participants chose the southern route on $62.8 \%$ of the trials and the northern route on only $37.2 \%$ of the trials $(S D=0.15$; see Figure 2). We performed a one-sample $t$ test on the sample proportion choosing south $(62.8 \%)$ versus the chance expected value $(50 \%)$ and found a significant effect $[t(63)=6.97, p<.01, d=0.81]$. Overall, 44 participants showed a southern route preference, 14 showed no preference, and 6 showed a northern route preference. On the east-west dilemma trials, however, the participants chose at chance level between the eastern route $(50.2 \%)$ and the western route $(49.8 \% ; S D=0.19)[t(63)=0.07$, $p>.05, d=0.01]$.

\section{Route Choice by Perspective}

Our second set of analyses focused on the extent to which the participants spontaneously produced perspectives predicted their choices on dilemma trials. To examine this question, we categorized individual trials by the perspective(s) used in the description of the route and then examined the participants' route selection on both types of dilemma trials. This process resulted in three perspective categories: egocentric, allocentric, and mixed. To analyze these data, we compared the sample proportion choosing south (to examine the north-south dilemma trials) or east (to examine the east-west dilemma trials) in each of the three term categories with the chance expected value $(50 \%)$. On the north-south dilemma trials, the participants showed a southern preference exceeding chance probability when they used egocentric terms $(64 \%)[t(44)=2.38$, $p<.05, d=0.45]$ or mixed terms $(69 \%)[t(14)=4.21$, $p<.01, d=1.11]$. This effect was marginal when they used allocentric terms $(56 \%)[t(17)=1.93, p=.07, d=$ $0.79]$. On the east-west dilemma trials, the participants did not show route selection preferences in any of the three perspective categories (all $t \mathrm{~s}<1, p \mathrm{~s}>.10$ ).

\section{Discussion}

Experiment 1's results demonstrate a distinct route selection preference; the participants disproportionately selected the southern over the northern routes during route-planning tasks. Critically, the northern and southern routes were the same length, and across participants, we controlled for initial segment length and the number of turns. Indeed, the only difference between the two route options was their direction in the canonical world. The participants generally chose the southern routes on approximately two thirds of the trials, only choosing the corresponding northern route on one third of the trials. To our knowledge, this is the first evidence of such an effect in human route planning.

There was also evidence that the southern route preferences were evident only when the participants spontaneously used an egocentric perspective to describe the routes (i.e., when the participants actively imagined movement through the environment from an embedded perspective). In contrast, we found minimal evidence for a southern route preference when the participant used a perspective external to the environment. However, this conclusion is tentative, given that the overall number of individuals who spontaneously produced allocentric or mixed perspectives was quite low, as is evidenced above by relatively low degrees of freedom in our analyses by perspective; that is, we may have insufficient power to identify a southern route preference when participants adopt allocentric perspectives. In Experiment 2, we addressed this possibility.

\section{EXPERIMENT 2 Forced Perspectives}

Our second experiment was designed to further examine the effects of spatial perspectives on route selection. In this experiment, we used the same paradigm as in our first experiment, but we added an induced perspective manipulation. In Experiment 1, the participants spontaneously produced various perspectives to describe routes, and in the present experiment, we asked participants to use only one of two perspectives: egocentric or allocentric. This manipulation reliably leads individuals to adopt alternate perspectives on an environment, altering both visual at-

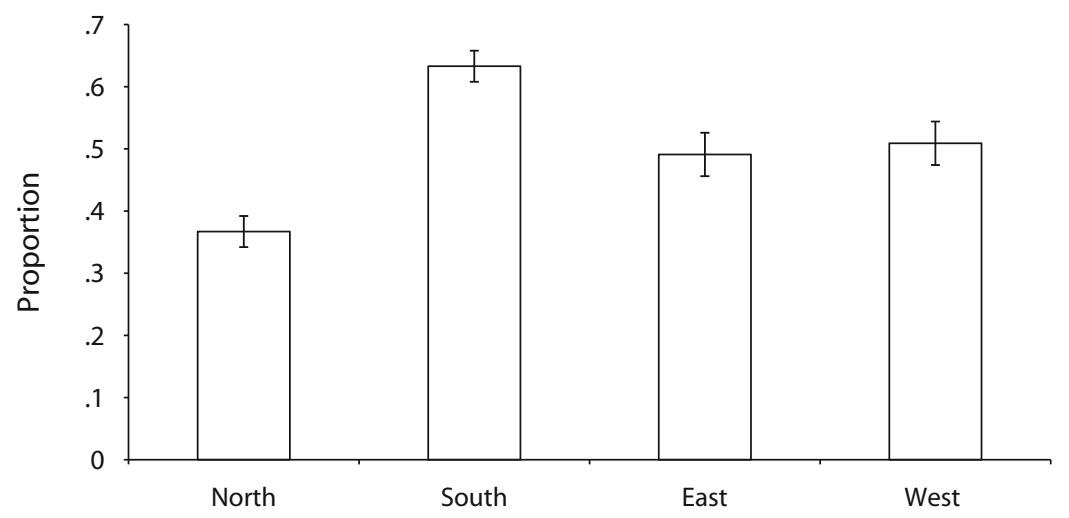

Figure 2. Experiment 1 mean proportion and standard error route selection for north and south routes (on the north-south dilemma trials) and east and west routes (on the east-west dilemma trials). 
tention during map study and subsequent spatial memory (i.e., Brunyé \& Taylor, 2009; Magliano et al., 1995; Taylor et al., 1999; van Asselen et al., 2006). We used this manipulation to examine whether encouraging participants to take either an egocentric or an allocentric perspective would differentially lead to southern route preferences during route planning. Given the Experiment 1 results, we expected that the former and not the latter perspective will produce the southern route preference.

\section{Method}

\section{Participants and Design}

Ninety-six Tufts University undergraduate students (57 female; mean age $=20.3$ years) participated for monetary compensation. We used a mixed design with perspective (egocentric, allocentric) varied between participants and dilemma type (north-south, eastwest) varied within participants. We measured the extent to which the participants chose each conflicting route option in the two dilemma type conditions as a function of perspective group.

\section{Materials}

The same maps and routes were used as in Experiment 1.

\section{Procedure}

All procedures were identical to those in Experiment 1 with the exception of the perspective manipulation. Prior to each of the two route-planning blocks, the participants were instructed to use either an egocentric or an allocentric perspective to describe their movement. In the egocentric group, the participants were told to use only the spatial terms forward, right, and left to describe movement through the environment; they were told that their instructions should refer to the changing position of a person within the environment, such as "go forward, turn right, turn left." In the allocentric group, the participants were told to use only the spatial terms north, south, east, and west to describe movement through the environment; they were told that their instructions should be relative to an outside bird's-eye view of the environment, such as "go north," or "continue west."

During pilot testing of this procedure, we noticed that some participants had difficulty adopting a particular perspective, and that this typically occurred only during the first trial of route planning. To avoid data contamination, we used a pseudorandomization scheme whereby all route-planning trials were presented in random order (as in Experiment 1), but with the exception that a nondilemma trial was always the first trial of each block.

\section{Results}

\section{Scoring and Analysis}

We recorded the chosen route and the perspective used to describe the route. We first examined overall route choice collapsed across perspective group; we then examined whether the selection of routes interacted with perspective group; and finally, separately for each of the two perspective groups, we analyzed the directions chosen in the two dilemma types. As in Experiment 1, all analyses were collapsed across map (Pittsburgh, Chicago) and map version (original, rotated $180^{\circ}$ ). Effect size is reported using Cohen's $d$.

\section{Conformity to Perspective Instructions}

When the participants showed difficulty adopting the intended perspective, the experimenter reiterated the instructions; subsequent to the first trial, all of the participants conformed to their perspective instructions.

\section{Route Choice}

Our first set of analyses was focused on the extent to which north-south or east-west dilemma trials were associated with decisions that departed from chance (50\%). When collapsed across perspective groups, on the northsouth dilemma trials, the participants chose the southern route on $57.2 \%$ of the trials and the northern route on $42.8 \%$ of the trials $(S D=0.20)$. We performed a onesample $t$ test on the sample proportion choosing south $(57.2 \%)$ versus the chance expected value $(50 \%)$ and found a significant effect $[t(95)=3.51, p<.01, d=$ $0.46]$. On the east-west dilemma trials, however, the participants were close to chance performance, choosing the eastern route on $49 \%$ of trials and the western route on $51 \%$ of trials $[t(95)=0.52, p>.05, d=0.06]$.

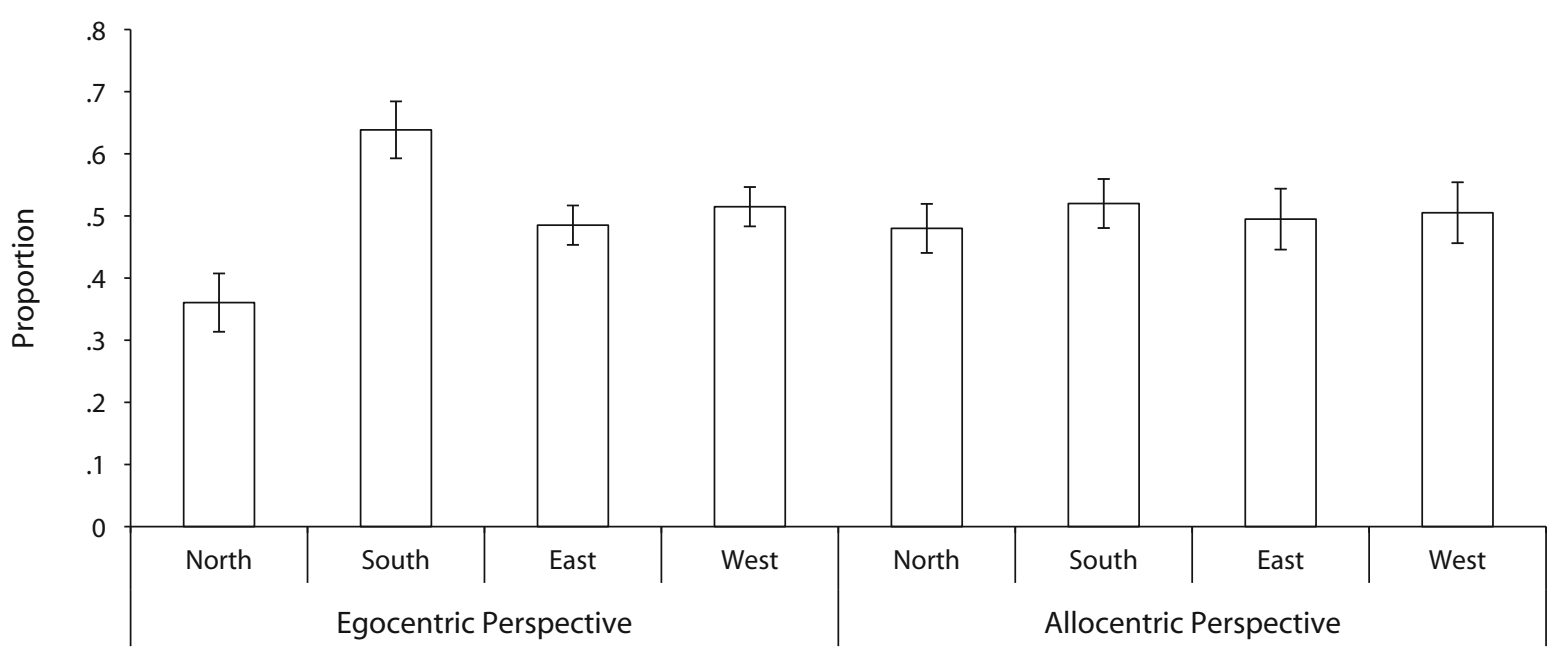

Figure 3. Experiment 2 mean proportion and standard error route selection for north and south routes (on the north-south dilemma trials) and east and west routes (on the east-west dilemma trials), as a function of perspective group. 


\section{Route Choice by Perspective}

To test for effects of perspective, we compared the sample proportion choosing south (to examine the northsouth dilemma trials) or east (to examine the east-west dilemma trials) in each of the two perspective groups with the chance expected value (50\%). In the egocentric group, the participants showed a southern preference exceeding chance performance $(63 \%)[t(47)=4.30, p<.01, d=$ $0.83]$; they did not show any preference on the east $(49 \%)$ versus west $(51 \%)$ trials $[t(47)=0.613, p>.05, d=$ 0.09 ] (see Figure 3). In the egocentric group, 34 participants showed a southern route preference, 11 showed a northern route preference, and 3 showed no preference. In the allocentric group, the participants did not show a southern preference; the proportion of southern route choice was $51.4 \%[t(47)=0.55, p>.05, d=0.09]$. Furthermore, these participants did not show any preference in the east $(49 \%)$ versus west $(51 \%)$ trials $[t(47)=$ $0.17, p>.05, d=0.03$ ]. In the allocentric group, 21 participants showed a southern route preference, 16 showed a northern route preference, and 11 showed no preference. Finally, we conducted an independent-samples $t$ test, which demonstrated that the proportion choosing southern routes was significantly higher in the egocentric $(63 \%)$ than in the allocentric $(51.4 \%)$ group $[t(94)=$ $2.96, p<.01, d=0.60]$.

\section{Discussion}

In our second experiment, we examined whether induced spatial perspectives could affect the extent to which participants show a southern route selection preference. Supporting the results of Experiment 1, an induced egocentric perspective led to a southern preference; these participants generally chose southern routes on approximately two thirds of the trials, choosing the corresponding northern route on only one third of the trials. In contrast, an induced allocentric perspective produced no particular preference.

It seems to be the case that participants reliably choose southern over northern routes when they take an embedded perspective during planning. Indeed, this is the case when participants spontaneously adopt, and when they are instructed to adopt, a particular perspective. That is, whether the participants are inherently predisposed to thinking about and communicating using egocentric terms (i.e., Pazzaglia \& De Beni, 2001) or instructed to adopt such a perspective regardless of any predisposition (i.e., Brunyé \& Taylor, 2009), they show similar southern route preferences. Participants appear to use heuristics that may be specifically activated when they take an embedded perspective on an environment. Indeed, embedded perspectives have been shown to activate similar mental imagery and brain areas as when people perform real-world actions (i.e., Brunyé et al., 2009; Ruby \& Decety, 2001). As such, southern route preferences elicited during route planning might be expected to reflect wayfinding behaviors in natural environments.

Why might a southern preference exist during route planning? In general, considering future actions is thought to activate motor simulations that allow an individual to imagine actions and their consequences on the world and themselves and to plan accordingly (i.e., Jeannerod, 2001; Knoblich \& Flach, 2001). Informal debriefings from Experiments 1 and 2 revealed that a handful of the participants misperceived the northern routes as more difficult or demanding, suggesting that this may have led to avoidance of those routes during planning. That is, north may be associated with moving uphill, as was suggested by the introductory quote from the Treebeard character in The Lord of the Rings. An initial segment strategy (i.e., Bailenson et al., 2000) that minimizes perceived effort may lead to the disproportionate selection of south-going routes. In fact, a number of studies have revealed that in action planning and perception, people consider current and predicted body states (e.g., Fajen, 2005; Knoblich \& Flach, 2001; Proffitt, 2006; Witt, Proffitt, \& Epstein, 2004); if participants misperceive north as uphill, this more physically demanding route would thus be avoided. Two alternative possibilities exist, however: First, the participants may have misperceived the northern routes as physically lengthier than the southern routes, and second, participants may simply have a preference to select options toward the bottom of the computer monitor. In Experiments 3 and 4, we ruled out these two alternative explanations.

\section{EXPERIMENT 3 Perceptions of Route Length}

Our third experiment was designed to test the possibility that participants misperceive northern routes as physically lengthier than southern routes. Length perception can be modulated by proximal spatial attention biases (i.e., preferentially attending to close versus far information) and/or the distance of judged lengths from participants' bodies (i.e., judging more distal information as lengthier than proximal information; see Kwon et al., 2004). Given our experimental configuration (all routes equally distal from the participants, given the vertical computer monitor alignment), we did not expect these factors to affect route length judgments. In the present experiment, participants completed a forced choice task involving the selection of one of two highlighted routes that went north or south, went east or west, or went in nonopposing directions.

\section{Method}

\section{Participants and Design}

Twenty-four Tufts University undergraduates (14 female; mean age $=20.7$ years) participated for monetary compensation. We used a within-participants design with dilemma type as the single independent variable. Our critical dependent measure was the extent to which the participants chose north over south options on tasks involving the forced choice of shorter or longer routes.

\section{Materials}

The same maps and routes were used as in the preceding experiments. A total of 160 images were created, each depicting two routes, one highlighted in red and one in blue. The images were made for each of the two map versions (Pittsburgh and Chicago), with 10 dilemma and 10 nondilemma trials per map (plus versions rotated $180^{\circ}$, for a total of 80 images). In 80 additional images, which routes 
were depicted in red or blue was reversed. As in the preceding experiments, the dilemma trials were either north-south or east-west dilemmas. The nondilemma trials depicted two routes, one of which was perceptibly longer than the other (with a minimum route length difference of $25 \%$ ) and did not fall evenly on north-south or eastwest axes.

\section{Procedure}

The participants were instructed to select either the shorter $(n=$ $12)$ or longer $(n=12)$ routes on each of 80 randomly presented trials. In a forced choice procedure, each participant chose the route highlighted either in red or in blue by pressing color-matched keys (the "C" and "M" keys, respectively).

\section{Results}

\section{Scoring and Analysis}

We recorded the chosen route and assessed whether route choice departed from chance $(50 \%)$ on north-south and east-west trials. For the nondilemma trials, we evaluated route-choice accuracy. No differences were found when we compared the choices of the participants instructed to make shorter versus longer route decisions $(p>.05)$ or when the northern and southern (or eastern and western) routes were depicted in blue or red $(p s<.05)$, so the data were collapsed across these groups (the longer route group data were reverse scored). Furthermore, no differences were found when we compared choices on the two maps (Pittsburgh, Chicago) or map versions (original, rotated $\left.180^{\circ}\right)(p \mathrm{~s}<.05)$. Effect size is reported using Cohen's $d$.

\section{Route Choice}

One-sample $t$ tests on the proportion choosing south $(49.5 \%)$ versus the chance expected value $(50 \%)$ did not reveal a significant effect $[t(23)=0.2, p>.10, d=0.04]$. Similar results were found when we examined the proportion choosing eastern routes $(54.7 \%)[t(23)=1.29, p>$ $.10, d=0.26]$. On the nondilemma trials, the participants generally selected the appropriate route $(M=95 \%, S E=$ 0.02 ), demonstrating that they understood and performed the task.

\section{Discussion}

There was no evidence that the participants misperceived the northern and southern (or eastern and western) routes as different in length. In conjunction with the results of Experiments 1 and 2, which demonstrated that adopted perspectives modulate route selection, the present results provide converging evidence that southern route selection preferences are not driven by a misperception of route length. In Experiment 4, we examined a second factor that may drive a southern route preference: the possibility that participants may prefer information toward the lower regions of the computer monitor.

\section{EXPERIMENT 4 Spatial Preferences by Monitor Region}

In our fourth experiment, we examined the possibility that southern route preferences may be driven by par- ticipants' preference to select options that appear in lower regions of the computer monitor (we thank an anonymous reviewer for pointing out this possibility). To test this, we presented participants with the same routes as those used in Experiment 3 but modified the stimuli to be devoid of geographical space cues (i.e., terrain, buildings, streets, compass); in these stimuli, origins and destinations were presented as black dots and alternate routes as blue versus red colored dots that provided competing options for connecting the two black dots. In this task, the participants connected presented origin and destination dots, responding in a single color to select either the upper (north) or the lower (south) option on the north-south dilemmas, and either the right (east) or the left (west) option on the eastwest dilemmas. If the participants preferentially select information from lower regions of the computer monitor, they should show lower-screen route selection probabilities exceeding chance $(50 \%)$.

\section{Method}

\section{Participants and Design}

Twenty-four Tufts University undergraduates (16 female; mean age $=20.1$ years) participated for monetary compensation. We used a within-participants design with dilemma type as the single independent variable. Our critical dependent measure was the extent to which the participants chose the lower over the upper option (and the left over the right option) when connecting dots between origins and destinations.

\section{Materials}

We used the same 160 images as in Experiment 3, modified in several ways. For each image, origin and destination buildings were replaced with single black dots. Each route option on those images was depicted by placing a colored dot at each turn along a possible route (one route depicted with red and the other with blue dots). All information other than the dots was then removed from the images (i.e., terrain, buildings, streets, compass rose, legend). In this way, the stimuli resembled a connect-the-dots puzzle involving the selection of either the blue or the red dots to connect the two black dots together. The overall structure of the images, however, remained identical to that of those in Experiment 3: The dilemma trials were either north-south (now upper-lower) or east-west (now right-left) dilemmas, and the nondilemma trials depicted two routes, one of which was perceptibly longer than the other (with a minimum route length difference of $25 \%$ ) and neither of which fell evenly on northsouth or east-west axes. Whether each route option appeared as red or blue, and which end was the origin, were both randomized across participants.

\section{Procedure}

The participants were instructed to select either the red or the blue series of dots to connect the two black dots together. In a forced choice procedure, each participant chose either the red or the blue series of dots by pressing colored keys (the " $\mathrm{C}$ " and " $\mathrm{M}$ " keys, respectively).

\section{Results}

\section{Scoring and Analysis}

We recorded the chosen route and assessed whether route choice departed from chance $(50 \%)$ on the upperlower and right-left trials. For the nondilemma trials, we evaluated route choice accuracy. The results did not vary as a function of route color (blue, red), map (Pittsburgh, 
Chicago), or map version (original, rotated $180^{\circ}$ ) ( $p$ s $>$ $.05)$, so the analyses were collapsed across these variables. Effect size is reported using Cohen's $d$.

\section{Route Choice}

One-sample $t$ tests on the proportion of participants choosing the lower routes $(48.9 \%)$ versus the chance expected value $(50 \%)$ did not reveal a significant effect $[t(23)=0.33, p>.10, d=0.07]$. Similar results were found when we examined the proportion choosing the right-side routes $(50.6 \%)[t(23)=0.30, p>.10, d=$ $0.04]$. On the nondilemma trials, the participants generally selected the route with fewer connecting dots (i.e., the shorter route; $M=79 \%, S E=0.02$ ).

\section{Discussion}

There was no evidence that the participants preferentially select the lower route options in a context devoid of geographic spatial cues. In conjunction with Experiment 3 , we provide evidence that the southern route preference cannot be accounted for by misperceptions of route length or by preferences to select information toward the lower region of the computer monitor. In Experiment 5, we examined the possibility that southern route preferences may in fact be driven by misperceptions of physical demand (i.e., north is up).

\section{EXPERIMENT 5 Perceptions of Physical Demand}

Experiment 5 was designed to test whether participants deem northern routes as more elevated (i.e., uphill) or physically demanding than southern routes. Participants rated depicted routes on four dimensions. One of the dimensions was directly related to assumed elevation (scenic potential), two were related to physical exertion (calorie expenditure, fuel consumption), and one was an unrelated filler dimension (traffic potential). We expect that if participants consider northern routes as moving generally up, they should also rate those routes as potentially more scenic (i.e., providing a vista given their relatively high elevation). They may also transfer this bias to ratings of calorie expenditure (relatively near transfer) and fuel consumption (relatively far transfer). We did not expect northern and southern route options to be differently rated in terms of traffic potential or any ratings to vary as a function of east- or west-going route options.

\section{Method}

\section{Participants and Design}

Sixty-four Tufts University undergraduate students (33 female; mean age $=20.3$ years) participated for monetary compensation. We used a within-participants design with route direction (north, south, east, west, nondirectional) as the single independent variable. Our dependent measure was the average rating on four dimensions: calorie consumption, fuel consumption, scenic potential, and traffic potential.

\section{Materials}

The same maps and routes were used as in Experiment 3, except that each depicted a single route highlighted in red. The routes went north, south, east, or west or in no single canonical direction (going somewhat diagonally across the map). Below the map was a rating scale that ranged from 1 to 9 with anchors corresponding to one of the four dimensions (e.g., fewest calories to most calories).

\section{Procedure}

The participants were instructed to use all possible information to rate each route. For calorie consumption, the participants were instructed to rate each route on the basis of how many calories a person might consume while walking the highlighted route. For fuel consumption, the participants were instructed to rate each route on the basis of how much fuel a person might burn while driving the highlighted route. For scenic potential, the participants were instructed to rate each route on the basis of how scenic the route might be in terms of scenic views and number of landmarks passed along the way (this latter characteristic was equated across routes). Finally, for traffic potential, the participants were instructed to rate each route on the basis of how much traffic they think someone might experience while traveling the route. Note that each of these instructions promotes a ground-level perspective. The participants used the number keypad to respond to each route trial. The trials were presented in random order within eight randomly presented blocks corresponding to rating type (scenery, calories, fuel, traffic) and map (Pittsburgh, Chicago). As in the preceding experiments, half of the participants saw the original map version, and half saw it rotated $180^{\circ}$.

\section{Results}

\section{Scoring and Analysis}

We evaluated average ratings (on a scale from 1 to 9) for each of the four rating types as a function of whether the route went north, south, east, or west.

\section{Route Ratings}

For scenery ratings, paired $t$ tests revealed that the scenery ratings were higher on the northern than on the southern routes $[t(63)=3.68, p<.01, d=0.46]$ and showed no difference between the eastern and western routes $[t(63)=0.85, p>.10, d=0.11]($ see Table 1$)$. For calorie ratings, paired $t$ tests revealed that the calorie ratings were marginally higher on northern than on southern routes $[t(63)=1.89, p=.06, d=0.24]$ and showed no difference between the eastern and western routes $[t(63)=1.1, p>.10, d=0.14]$. For the fuel ratings, paired $t$ tests revealed that fuel ratings were not different for the northern and southern routes $[t(63)=0.15$, $p>.10, d=0.02]$ or for the eastern and western routes $[t(63)=0.27, p>.10, d=0.03]$. Finally, for the traffic ratings, paired $t$ tests revealed that traffic ratings were not different for the northern and southern routes $[t(63)=$ $0.29, p>.10, d=0.04]$ or for the eastern and western routes $[t(63)=1.03, p>.10, d=0.13]$.

\section{Discussion}

Experiment 5 demonstrated that participants rate north-going routes as having higher potential for scenery and as being associated with higher calorie consumption relative to south-going routes. In terms of scenery, it seems that participants deem northern routes as generally traveling uphill relative to southern ones, providing more opportunities for scenic vistas at elevation. We find no other reasonable explanation for higher scenery rat- 
Table 1

Experiment 5 Mean Ratings and Standard Errors for North and South Routes (Derived From North-South Dilemma Trials) and East and West Routes (Derived From East-West Dilemma Trials) As a Function of Rating Type

\begin{tabular}{|c|c|c|c|c|c|c|c|c|}
\hline \multirow[b]{3}{*}{ Rating Type } & \multicolumn{8}{|c|}{ Route Type } \\
\hline & \multicolumn{2}{|c|}{ North } & \multicolumn{2}{|c|}{ South } & \multicolumn{2}{|c|}{ East } & \multicolumn{2}{|c|}{ West } \\
\hline & $M$ & $S E$ & $M$ & $S E$ & $M$ & $S E$ & $M$ & $S E$ \\
\hline Scenery & 4.62 & 0.13 & 4.12 & 0.10 & 4.48 & 0.11 & 4.54 & .10 \\
\hline Calories & 4.32 & 0.13 & 4.17 & 0.10 & 4.35 & 0.10 & 4.41 & .09 \\
\hline Fuel & 3.91 & 0.09 & 3.92 & 0.09 & 4.11 & 0.10 & 4.09 & .09 \\
\hline Traffic & 4.16 & 0.09 & 4.14 & 0.10 & 4.45 & 0.10 & 4.50 & .10 \\
\hline
\end{tabular}

ings, given that all physical visual factors were equated across the north and south route conditions (e.g., number of landmarks, number of intersections). Converging evidence suggesting that northern routes are misperceived as generally uphill emerges from the fact that the participants rated north-going routes as associated with somewhat higher calorie consumption. This second effect suggests that the uphill journey associated with the northern routes would be more physically demanding for a traveler; note, however, that this effect reached only marginal significance. To further examine perceptions of relative difficulty and to extend the present results to a larger scale environment, in Experiment 6, we tested whether participants would estimate north-going routes as more time consuming to travel than south-going routes, using a U.S. road atlas.

\section{EXPERIMENT 6 Travel Time in Large-Scale Environments}

Experiment 6 was designed to test the notion that northgoing routes are misperceived as more demanding than south-going routes. To do so, we asked participants to judge the amounts of time that it would take to travel routes between U.S. cities; in general, travel time estimates are sensitive to predicted changes in travel speed due to such variables as weather, topography, and traffic (Fuller et al., 2009; Selten, Chmura, Pitz, Kube, \& Schreckenberg, 2007; Svenson, 2008). In the present study, participants provided estimates for routes running east to west, west to east, north to south, south to north, and diagonal (filler trials) across the map. Origins and destinations were reversed across blocks, and we examined the extent to which participants predicted longer travel times as a function of route travel direction. We expected that if the participants considered north-going routes as moving generally uphill, they should also estimate longer travel times relative to when the same route moves north to south. Given the results of Experiment 5, we did not expect that travel time estimates would vary as a function of whether the routes were east- or west-going.

\section{Method}

\section{Participants and Design}

Twenty-four Tufts University undergraduate students (13 female; mean age $=19.6$ years) participated for monetary compensation. We used a within-participants design with route travel direction (north-going vs. south-going, east-going vs. west-going) as the single independent variable. Our dependent measure was average time estimate (in hours).

\section{Materials}

Using the Google Maps utility at a zoom level of 200 miles per linear inch, we plotted 30 routes, 10 of which ran along the longitudinal (north-south) axis, 10 of which ran along the latitudinal (east-west) axis, and 10 of which were fillers that had no single canonical travel direction (fillers, typically diagonally oriented). Route length varied widely, from 183 to 2,065 miles, with a mean length of 798 miles. Within each set of 10 routes, the origin and destination cities (e.g., San Francisco to Portland, OR) were similar in elevation; this was confirmed in three $t$ tests comparing origin and destination elevations, which revealed no significant difference in the north-south set $[t(9)=0.07, p>.05, d=0.02]$, the east-west set $[t(9)=0.36, p>$ $.05, d=0.11]$, or the filler set $[t(9)=0.67, p>.05, d=0.21]$. The 30 route images were each $1,200 \times 700$ pixels in resolution.

\section{Procedure}

The participants were instructed to use all possible information to estimate how much time it would take to travel from a presented origin to a destination, such as topography, weather patterns, traffic, and travel speed. The participants were given a text description of a route (e.g., San Francisco to Portland, OR) in the center of the screen; the description was then removed, and the corresponding route image was depicted on the screen. For each description-image pair, the participants were instructed to enter (using a number keypad) a predicted travel time for the route (in hours). The participants were presented with two blocks, each containing the same 30 route images; in the first block, half of the north-south routes went from north to south, and half went from south to north (the east-west routes and the fillers were structured in an identical manner). Across blocks, the travel direction of each route was reversed to allow us to compare time estimates of the same routes, but in the opposite travel direction. To ensure that the participants attended to which city was the origin and which was the destination, they were tested on their memory for the pairs immediately following the first block of 30 description-image pairs.

\section{Results}

\section{Scoring and Analysis}

We evaluated average time estimates (in hours) for north- versus south-going routes and for east- versus westgoing routes. To do so, we conducted two paired $t$ tests, one comparing mean time estimates for the north- versus south-going routes, and one comparing estimates for the east- versus west-going routes.

\section{Travel Time Estimation}

Time estimates given to the north-going routes $(M=$ $17.43 \mathrm{~h}, S E=1.28)$ were greater than those given to 
the paired south-going routes $(M=15.78 \mathrm{~h}, S E=1.16)$ $[t(23)=2.92, p<.01, d=0.60]$. This effect was not found when comparing the east-going $(M=15.66 \mathrm{~h}, S E=1.35)$ with the paired west-going routes $(M=16.23 \mathrm{~h}, S E=$ 1.35) $[t(23)=0.64, p>.05, d=0.13]$.

\section{Discussion}

Experiment 6 demonstrated that participants provide greater travel time estimates for north-going than for south-going routes; in contrast, the participants did not provide different travel time estimates as a function of whether the route was east- or west-going. Interestingly, these travel time differences persisted despite the origins and destinations being equated in actual elevation, the travel tasks taking place in a highly familiar environment, and the opposing-direction routes being identical in length, origin, and destination. In conjunction with Experiment 5, we provide converging evidence that traveling north is misperceived as more effortful or difficult (i.e., north is uphill) relative to traveling south, even when making judgments in a large-scale and relatively familiar environment.

\section{GENERAL DISCUSSION}

In Experiments 1 and 2, we demonstrated a reliable bias wherein route planners chose southern over equivalently long northern route options when assuming an egocentric perspective. Indeed, the participants tended to choose a northern route option on only about one third of the north-south dilemma trials, indicating a strong preference toward southern route options. Despite its strength and reliability, during debriefing sessions, many of the participants were not aware of their bias, and only a handful suggested that the northern routes were somehow more difficult or demanding options. When probed further, these latter participants seemed aware that their suggestions were unfounded, and many were even surprised and puzzled by their own behavior.

We were also able to delineate some of the possible sources for the southern route selection bias. First, the participants modulated their route selection behaviors as a function of spatial perspective. The participants produced rather symmetric decisions, choosing northern and southern routes on approximately half of the trials, when they spontaneously used or were instructed to use an allocentric perspective. This perspective involves taking an outside bird's-eye perspective and referencing movement through an environment to a canonical coordinate system. In contrast, the participants produced asymmetric decisions, preferentially selecting southern route options approximately two thirds of the time when they spontaneously used or were instructed to use an egocentric perspective. This perspective links navigation movements to the body axes of an imagined individual moving through the environment, and thus represents an embedded or immersed perspective on described movement. The egocentric perspective was not only the most commonly used when the participants were provided with the flexibility to choose their own perspectives, it also produced the high- est rate of southern route selection. Interestingly, egocentric perspectives have been shown to activate similar mental imagery and brain areas as when people perform real-world actions, suggesting that the behavior patterns associated with this perspective might be a result of the integration of real-world perceptual and motor experiences into everyday decision making (Barsalou, 2008; Brunyé et al., 2009; Ditman et al., 2010; Glenberg, 2007; Ruby \& Decety, 2001). Indeed, some work shows that people perform motor simulations of intended actions, and these motor simulations are responsible for distorted spatial judgments during distance and perceived slant estimations (Seeley \& Waughtel, 2008; Witt \& Proffitt, 2008 ). We suggest that motor simulations of navigation influence path selection and guide whether the southern route heuristic is incorporated into the decision-making process.

Participants appear to misperceive northern routes as traveling uphill relative to southern routes, which was revealed when the participants rated routes on a variety of dimensions and estimated travel times for routes between U.S. cities. First, the participants rated northern routes as having a higher potential for scenic views, suggesting that they misattributed higher elevations to northern routes. More evidence came from the fact that the participants rated the northern routes as somewhat higher in terms of predicted calorie expenditure. That is, the participants predicted that travelers would burn more calories walking northern than walking southern routes. The misperception that northern routes are directed uphill is somewhat puzzling, given that, under this rationale, uphill path segments would be offset by later downhill path segments. Specifically, most of the north-south dilemma trials had three path segments, one moving generally north from an origin, one moving somewhat horizontally across the map (due east or west), and then the final path segment moving south toward the destination. We suggest that this effect might be due to the misperception that northern routes are directed uphill but that the participants' decisions are further guided by a focus on the initial path segment, as was suggested by earlier work (i.e., Bailenson et al., 1998, 2000; Conroy Dalton, 2003; Hochmair \& Frank, 2002). That is, the participants may have been most dependent on the initial path segment for making route selections, and if this initial path segment was deemed as directed uphill (because of its northward orientation), this dependence may have led to a northern route aversion. Another possibility is that the participants integrated knowledge of physical momentum and considered that traveling downhill on an initial path segment (i.e., south) would ultimately lead to less energy expenditure on the uphill path segment; this possibility meshes nicely with the notion that route planners strive to minimize cognitive and physical effort (Christenfeld, 1995; Freksa, 1999). This latter possibility, however, cannot explain the increased time estimates for long-distance routes between U.S. cities found in Experiment 6 . The participants applied the north-up heuristic to travel planning in large-scale and familiar environments, when there were no potential advantages of physical momentum with one route relative to another. 
Many heuristics can be reliably evoked in experimental laboratory tasks, and some evidence suggests that they also manifest themselves in natural environments. Indeed, in most studies in which route planning was examined, maps of realistic environments, such as college campuses, towns, and/or cities (e.g., Bailenson et al., 1998, 2000; Christenfeld, 1995) were used. Furthermore, in some work route-planning heuristics in natural environments have been reliably replicated, such as by observations of students navigating a college campus or shopping center (Christenfeld, 1995; Gärling \& Gärling, 1988; Shum, Bailenson, Hwang, Piland, \& Uttal, 1998). One assumption in the present work is that the spatial processes involved in route planning and their behavioral results are similar whether someone verbally reports or memorizes and eventually travels a proposed route; to our knowledge, however, no one has directly tested this hypothesis. A possibility for future researchers, therefore, is to examine whether the present results can be replicated with alternate response mechanisms, such as whether a participant verbally reports versus draws a route on a map; indeed, the latter may more accurately reflect the process of naturalistic route planning (we thank an anonymous reviewer for pointing out this possibility). However, given the realism of our small-scale and large-scale maps, and the past evidence suggesting that spatial heuristics manifest themselves in both laboratory and real-world settings, we expect that the current effects would be replicated in real-world environments; in future work in our laboratory, we will test this hypothesis in pedestrian and driving contexts using virtual reality.

Our results further suggest that the southern route preference does not necessarily reflect inherent perceptual biases (such as length/distance perception) but, rather, reflects higher level conceptual heuristics that shape the representation of space. A remaining question is the source of such heuristics. One possibility is that the geographic region of the present university sample is characterized by higher elevations to the north (i.e., White Mountains in New Hampshire, Green Mountains in Vermont) and lower elevations to the south (i.e., large sea-level regions in Rhode Island and Connecticut). In Experiments 1, 2, and 4 , it could be the case that the participants transferred their knowledge of large-scale regional space to decisions made on relatively small-scale and unfamiliar environments. This possibility is limited, however, in that the majority of the Tufts undergraduate population (76\%) is from states other than Massachusetts, with only approximately $30 \%$ being from the New England region. Furthermore, these students made biased time estimates when the environment (the U.S.) was both familiar and remote. In future work, however, whether the effects found in Experiments 1 and 2 can be replicated in geographic regions characterized by opposite elevation patterns, such as Pittsburgh (which has the Appalachian Mountains to the south), or in participant groups who have lived primarily in such areas should be examined.

Another possibility is that participants transfer their knowledge of gravity (moving upward is more difficult than moving downward) to decisions made using maps viewed perpendicular to the ground. That is, the computer monitor orientation perhaps makes upward movement (i.e., north) seem more difficult than downward movement (i.e., south). This possibility does not seem particularly likely, given that even though the computer monitor orientation was held constant, the southern route selection bias diminished with the use of the allocentric perspective. An additional remaining question is the extent to which a southern route selection preference will exist when northern route options become perceptibly shorter in length. Indeed, some work suggests that spatial heuristics are strong enough to bias route selection even when a shorter route exists (Bailenson et al., 1998, 2000), and this is an exciting possibility for future research.

Selecting and planning routes through an environment are critical parts of everyday navigation, whether in a car, on foot, or on a bicycle. Predicting these behaviors is an exceedingly complex task, not only given that route planners consider which route is seemingly shorter or more efficient, but also given several heuristics that guide and constrain their selections. Indeed, accurate prediction of wayfinding behavior can be performed only by considering, at least, that participants tend to deviate minimally from the global direction of a goal destination; select routes on the basis of the straightness of an initial path segment; choose routes containing the fewest number of turns and landmarks; tend to delay route decisions until late in travel, when several equivalent options exist; and in the present case, tend to prefer southern rather than northern routes when adopting an egocentric perspective during route planning (Bailenson et al., 1998, 2000; Christenfeld, 1995; Conroy Dalton, 2003; Hochmair \& Frank, 2002; Sadalla \& Staplin, 1980; Seneviratne \& Morrall, 1986). In most cases, spatial heuristics are thought to minimize cognitive effort while maintaining somewhat satisfactory choices, but in other cases, we know that heuristics can negatively affect people's judgments and impair task performance (Newcombe, Huttenlocher, Sandberg, \& Lie, 1996; A. Tversky, 1977; A. Tversky \& Kahneman, 1983). Defining heuristics and quantifying their effects on human route planning is critical to understanding, modeling, and predicting human navigation.

\section{AUTHOR NOTE}

The opinions expressed herein are those of the authors and not necessarily of the United States Army. We thank Kiran Lokhande and William Shirer for their careful data collection and scoring. Correspondence concerning this article should be addressed to T. T. Brunyé, Department of Psychology, Tufts University, 490 Boston Ave., Medford, MA 02155 (e-mail: tbruny01@tufts.edu).

\section{REFERENCES}

Bailenson, J. N., Shum, M. S., \& UtTal, D. H. (1998). Road climbing: Principles governing asymmetric route choices on maps. Journal of Environmental Psychology, 18, 251-264.

Bailenson, J. N., Shum, M. S., \& UtTal, D. H. (2000). The initial segment strategy: A heuristic for route selection. Memory \& Cognition, 28, 306-318.

Barsalou, L. W. (2008). Grounded cognition. Annual Review of Psychology, 59, 617-645.

Benshoof, J. A. (1970). Characteristics of drivers' route selection behavior. Traffic Engineering \& Control, 11, 604-606. 
Bovy, P. H. L., \& STERn, E. (1990). Route choice: Wayfinding in transport networks. Transportation Research Part A: Policy \& Practice, 27, 338-339

Brunyé, T. T., Ditman, T., Mahoney, C. R., Augustyn, J. S., \& TAYLOR, H. A. (2009). When you and I share perspectives: Pronouns modulate perspective-taking during narrative comprehension. Psychological Science, 20, 27-32.

BRUNYÉ, T. T., RAPP, D. N., \& TAYLOR, H. A. (2008). Representational flexibility and specificity following spatial descriptions of real world environments. Cognition, 108, 418-443.

BRUnyÉ, T. T., \& TAYLOR, H. A. (2008a). Extended experience benefits spatial mental model development with route but not survey descriptions. Acta Psychologica, 127, 340-354.

BRUNYÉ, T. T., \& TAYLOR, H. A. (2008b). Working memory in developing and applying mental models from spatial descriptions. Journal of Memory \& Language, 58, 701-729.

Brunyé, T. T., \& TAYLOR, H. A. (2009). When goals constrain: Eye movements and memory for goal-oriented map study. Applied Cognitive Psychology, 23, 772-787.

Christenfeld, N. (1995). Choices from identical options. Psychological Science, 6, 50-55.

Conroy Dalton, R. (2003). The secret is to follow your nose: Route path selection and angularity. Environment \& Behavior, 35, 107-131.

Ditman, T., Brunyé, T. T., Mahoney, C. R., \& Taylor, H. A. (2010). Simulating an enactment effect: Pronouns guide action simulation during narrative comprehension. Cognition, 115, 172-178.

FAJEN, B. R. (2005). Perceiving possibilities for action: On the necessity of calibration and perceptual learning for the visual guidance of action. Perception, 34, 717-740.

FinCHER-KIEFER, R. (2001). Perceptual components of situation models. Memory \& Cognition, 29, 336-343.

FisCHER, M. H., \& ZwAAN, R. A. (2008). Embodied language: A review of the role of the motor system in language comprehension. Quarterly Journal of Experimental Psychology, 61, 825-850.

FreKsa, C. (1999). Spatial aspects of task-specific wayfinding maps. In J. S. Gero \& B. Tversky (Eds.), Visual and spatial reasoning in design (pp. 15-32). University of Sydney: Key Centre of Design Computing and Cognition.

Fuller, R., Gormley, M., Stradling, S., Broughton, P., KinNEAR, N., O'Dolan, C., \& HaNnigan, B. (2009). Impact of speed change on estimated journey time: Failure of drivers to appreciate relevance of initial speed. Accident Analysis \& Prevention, 41, 10-14.

GärLING, T., \& GäRLING, E. (1988). Distance minimization in downtown pedestrian shopping. Environment \& Planning A, 20, 547-554.

Gärling, T., LindBERG, E., \& MäNTYLÄ, T. (1983). Orientation in buildings: Effects of familiarity, visual access, and orientation aids. Journal of Applied Psychology, 68, 177-186.

GLENBERG, A. M. (2007). Language and action: Creating sensible combinations of ideas. In G. Gaskell (Ed.), The Oxford handbook of psycholinguistics (pp. 361-370). Oxford: Oxford University Press.

GlenberG, A. M., \& KaschaK, M. P. (2002). Grounding language in action. Psychonomic Bulletin \& Review, 9, 558-565.

Golledge, R. (1995). Path selection and route preference in human navigation: A progress report. In A. U. Frank \& W. Kuhn (Eds.), Spatial information theory: A theoretical basis for GIS (COSIT '95) (Lecture Notes in Computer Science, No. 988, pp. 207-222). Berlin: Springer.

Golledge, R. (1999). Wayfinding behavior: Cognitive mapping and other spatial processes. Baltimore: Johns Hopkins University Press.

Heth, C. D., \& Cornell, E. H. (1998). Characteristics of travel by persons lost in Albertan wilderness areas. Journal of Environmental Psychology, 18, 223-235.

Hochmair, H. H., \& Frank, A. U. (2002). Influence of estimation errors on wayfinding decisions in unknown street networks-Analyzing the least-angle strategy. Spatial Cognition \& Computation, 2, 283-313.

HochmaIr, H. H., \& KarLsson, V. (2005). Investigation of preference between the least-angle strategy and the initial segment strategy for route selection in unknown environments. In C. Freksa, M. Knauff, B. Krieg-Brückner, B. Nebel, \& T. Barkowskey (Eds.), Spatial cognition IV (LNAI 3343, pp. 79-97). Berlin: Springer.

Hölscher, C., Meilinger, T., Vrachliotis, G., Brösamle, M., \& KNAUfF, M. (2006). Up the down staircase: Wayfinding strategies in multi-level buildings. Journal of Environmental Psychology, 26, 284-299.

JACOBY, H. (1917). Navigation. New York: MacMillan.

Janzen, G., Herrmann, T., Katz, S., \& Schweizer, K. (2000). Oblique angled intersections and barriers: Navigating through a virtual maze. In C. Freksa, W. Brauer, \& K. F. Wender (Eds.), Spatial Cognition II (LNCS 1849, pp. 277-294). Berlin: Springer.

JEANNEROD, M. (2001). Neural simulation of action: A unifying mechanism for motor cognition. NeuroImage, 14, S103-S109.

KNOBLICH, G., \& FlaCh, R. (2001). Predicting the effects of actions: Interactions of perception and action. Psychological Science, 12, 467472.

KuIPERs, B. (2000). The spatial semantic hierarchy. Artificial Intelligence, 119, 191-233.

Kwon, J. C., Lee, B. H., Ji, J. M., Jeong, Y., Kim, B. J., Heilman, K. M., \& NA, D. L. (2004). Length perception and production of normal subjects in proximal versus distal peripersonal space. Journal of the International Neuropsychological Society, 10, 913-919.

LEVELT, W. J. M. (1982). Cognitive styles in the use of spatial direction terms. In R. J. Jarvella \& W. Klein (Eds.), Speech, place and action. Studies in deixis and related topics (pp. 251-268). Chichester: Wiley.

LEvine, M. (1982). You-are-here maps: Psychological considerations. Environment \& Behavior, 14, 221-237.

Magliano, J. P., Cohen, R., Allen, G. L., \& Rodrigue, J. R. (1995). The impact of a wayfinder's goal on learning a new environment: Different types of spatial knowledge as goals. Journal of Environmental Psychology, 15, 65-75.

Montello, D. R. (1998). A new framework for understanding the acquisition of spatial knowledge in large-scale environments. In M. J. Egenhofer \& R. G. Golledge (Eds.), Spatial and temporal reasoning in geographic information systems (pp. 143-154). New York: Oxford University Press.

Montello, D. R. (2005). Navigation. In P. Shah \& A. Miyake (Eds.), The Cambridge handbook of visuospatial thinking (pp. 257-294). Cambridge: Cambridge University Press.

Newcombe, N., Huttenlocher, J., SAndberg, E., \& Lie, E. (1996). What do asymmetries in judgment indicate about representation? The case of spatial estimation. Paper presented at the 37th Annual Meeting of the Psychonomic Society, Chicago.

Pazzaglia, F., \& De Beni, R. (2001). Strategies of processing spatial information in survey and landmark-centred individuals. European Journal of Cognitive Psychology, 13, 493-508.

ProffitT, D. R. (2006). Embodied perception and the economy of action. Perspectives on Psychological Science, 1, 110-122.

RAUBAL, M. (2002). Wayfinding in built environments: The case of airports. Solingen, Germany: Natur \& Wissenschaft.

Richardson, D. C., Spivey, M. J., Barsalou, L. W., \& McRae, K. (2003). Spatial representations activated during real-time comprehension of verbs. Cognitive Science, 27, 767-780.

Ruby, P., \& DeceTY, J. (2001). Effect of subjective perspective taking during simulation of action: A PET investigation of agency. Nature Neuroscience, 4, 546-550.

SAdalla, E. K., \& Staplin, L. J. (1980). The perception of traversed distance: Intersections. Environment \& Behavior, 12, 167-182.

Scharine, A. A., \& McBeath, M. K. (2002). Right-handers and Americans favor turning to the right. Human Factors, 44, 248-256.

SeEley, W. P., \& WAUGhtel, J. (2008). Motor simulation \& the effects of energetic \& emotional costs of depicted actions in picture perception. Journal of Vision, 8(6), 1041.

Selten, R., Chmura, T., Pitz, T., Kube, S., \& Schreckenberg, M. (2007). Commuters route choice behavior. Games \& Economic Behavior, 58, 394-406.

Seneviratne, P. N., \& Morrall, J. F. (1986). Analysis of factors affecting the choice of route of pedestrians. Transportation Planning \& Technology, 10, 147-159.

Shum, M. S., Bailenson, J., Hwang, S., Piland, L., \& Uttal, D. (1998). Road climbing: Principles of route choice. In Proceedings of the 20th Annual Conference of the Cognitive Science Society. Mahwah, NJ: Erlbaum.

Svenson, O. (2008). Decisions among time saving options: When intuition is strong and wrong. Acta Psychologica, 127, 501-509. 
TAYlor, H. A., NaYlor, S. J., \& Chechile, N. A. (1999). Goal-specific influences on the representation of spatial perspective. Memory \& Cognition, 27, 309-319.

TAYlor, H. A., \& TVERsky, B. (1992a). Descriptions and depictions of environments. Memory \& Cognition, 20, 483-496.

TAYLOR, H. A., \& TVERSKY, B. (1992b). Spatial mental models derived from survey and route descriptions. Journal of Memory \& Language, 31, 261-292.

Tversky, A. (1977). Features of similarity. Psychological Review, 84, 327-352.

TVersky, A., \& Kahneman, D. (1983). Extensional versus intuitive reasoning: The conjunction fallacy in probability judgment and choice. Psychological Review, 90, 293-315.

Tversky, B. (2009). Spatial cognition: Embodied and situated. In P. Robbins \& M. Aydede (Eds.), The Cambridge handbook of situated cognition (pp. 201-217). Cambridge: Cambridge University Press.

UeberschaER, M. H. (1971). Choice of routes on urban networks for the journey to work. Highway Research Record, 369, 228-238.

van Asselen, M., Fritschy, E., \& Postma, A. (2006). The influence of intentional and incidental learning on acquiring spatial knowledge during navigation. Psychological Research, 70, 151-156.
Weisman, J. (1981). Evaluating architectural legibility: Way-finding in the built environment. Environment \& Behavior, 13, 189-204.

Wiener, J. M., LAFON, M., \& BerThOZ, A. (2008). Path planning under spatial uncertainty. Memory \& Cognition, 36, 495-504.

Wiener, J. M., \& Mallot, H. A. (2003). "Fine-to-coarse" route planning and navigation in regionalized environments. Spatial Cognition \& Computation, 3, 331-358.

Wiener, J. M., Schnee, A., \& Mallot, H. A. (2004). Use and interaction of navigation strategies in regionalized environments. Journal of Environmental Psychology, 24, 475-493.

WitT, J. K., \& ProffitT, D. R. (2008). Action-specific influences on distance perception: A role for motor simulation. Journal of Experimental Psychology: Human Perception \& Performance, 34, 1479-1492.

Witt, J. K., Proffitt, D. R., \& Epstein, W. (2004). Perceiving distance: A role of effort and intent. Perception, 33, 570-590.

Yoshino, R. (1991). A note on cognitive maps: An optimal spatial knowledge representation. Journal of Mathematical Psychology, 35, 371-393.

(Manuscript received September 1, 2009; revision accepted for publication January 19, 2010.) 